\title{
The Used of Aqueous Urea Solution in Reduction of Noxious Emissions in Bio Fuel Combustion System Using Selective Non-Catalytic Reduction
}

\author{
Mohamad Shaiful Ashrul Ishak \\ School of Manufacturing Engineering, Universiti Malaysia Perlis \\ PO Box 77, Pejabat Pos Besar, 01000 Kangar, Perlis, Malaysia \\ Tel: +604-9885035, Fax: +604-9885034, E-mail: mshaiful@unimap.edu.my \\ Mohammad Nazri Mohd. Jaafar \\ Department of Aeronautics \& Automotive, Faculty of Mechanical Engineering \\ Universiti Teknologi Malaysia, 81310 UTM, Johor, Malaysia
}

Received: May 12, 2011

Accepted: June 17, 2011

doi:10.5539/mas.v5n4p30

The research is financed by Ministry of Science, Technology and Innovation Malaysia (MOSTI) under Science Fund Grant Scheme (06-01-15-SF0034).

\begin{abstract}
Selective Non-Catalytic Reduction (SNCR) of nitric oxide was studied experimentally by injecting different concentrations of aqueous urea solution; urea and ammonia in a pilot-scale Bio-fuel fired tunnel furnace at 3-4 \% excess oxygen level and with low ppm of baseline $\mathrm{NO}_{\mathrm{x}}$ ranged from 65 to $75 \mathrm{ppm}$ within the investigated temperature range. The furnace simulated small-scale combustion systems where the operating temperatures are usually in the range of about 973 to $1323 \mathrm{~K}$ and $\mathrm{NO}_{\mathrm{x}}$ emission level remains below $100 \mathrm{ppm}$. $\mathrm{NO}_{\mathrm{x}}$ reductions were studied with the variation of different parameters such as injection temperature, residence time, Normalized Stoichiometric Ratio (NSR) of the reagent, carrier gas pressure, etc. A significant result shows that for NSR, at higher NSR, ammonia could give significant reduction of $\mathrm{NO}_{\mathrm{x}}$ at the investigated injection temperature. Meanwhile, for the effect of residence time, both aqueous solution shows that the $\mathrm{NO}_{\mathrm{x}}$ reduction increased with increase in residence time. Finally for the effect on injection temperature, both aqueous solution, up to a certain temperature $\mathrm{NO}_{\mathrm{x}}$ reduction continued to increase with increasing injection temperature and afterward the reduction decayed with further increase in temperature.
\end{abstract}

Keywords: Combustion, Bio-fuel, Aqueous Urea Solution, $\mathrm{NO}_{\mathrm{x}}$ Reduction, Selective Non-Catalytic Reduction (SNCR)

\section{Introduction}

Selective Non-Catalytic Reduction (SNCR) involves the injection of a reducing reagent into the combustion effluent at relatively higher temperatures to react with $\mathrm{NO}_{\mathrm{x}}$. The reaction between $\mathrm{NO}_{\mathrm{x}}$ and $\mathrm{NO}_{\mathrm{x}}$ reducing agent occurs in a temperature window of 1144 to $1366 \mathrm{~K}$. Above this temperature window, the reagent might be oxidized resulting in the formation of additional $\mathrm{NO}_{\mathrm{x}}$ and below the window the rate of reaction becomes slow which may result in excessive ammonia slip (Rota, 2002). Some additives are applied to widen the reaction temperature range. If urea is used, the temperature window ranges from 1199 to $1310 \mathrm{~K}$. However, with the addition of additives, the effective temperature range expands to 1088 to $1421 \mathrm{~K}$. In general, $\mathrm{NO}_{\mathrm{x}}$ reductions are lower and chemical consumption is higher as compared to Selective Catalytic Reduction (SCR) (Ishak and Jaafar, 2011). Typical reagent/inlet $\mathrm{NO}_{\mathrm{x}}$ stoichiometries are 2:1. Since SNCR does not require the use of a catalyst, capital costs are lower than with SCR. A number of reagents can be used as $\mathrm{NO}_{\mathrm{x}}$ reducing agents. But most common of them are ammonia and urea. The urea may be stored as a solid or mixed with water and stored as a solution.

\section{2. $\mathrm{NO}_{\mathrm{x}}$ Reduction Using Aqueous Urea Solution}

Historically, urea based selective non-catalytic reduction was invented after the thermal $\operatorname{DeNO}_{\mathrm{x}}$ process which uses the ammonia as reducing agent. Arand et al. (1980) first reported that urea could be used as reducing agent in form of either solid or solution at temperatures in excess of $977 \mathrm{~K}$ and in the presence of at least $0.1 \%$ (volume based) oxygen. He conducted his experiment in a natural gas fired combustor of about $200 \mathrm{~mm}$ diameter. Few investigations have studied the thermal decomposition mechanism of urea. Under some conditions, urea decomposed into equal amounts of $\mathrm{HNCO}$ and $\mathrm{NH}_{3}$ (Chen et al., 1988; Jodal et al., 1990; Caton and Seibers, 1989). Jodal believed that the thermal breakdown of urea at temperatures significantly above $593 \mathrm{~K}$ would lead 
directly to $\mathrm{NH}_{2}$ and eventually NCO radicals in equal proportions. Salimian and Handson (1980) showed that urea might rapidly decompose to give amidogen radicals directly. They performed a modeling calculations based on their reaction mechanism that predicted that the peak $\mathrm{NO}_{\mathrm{x}}$ removal efficiency is comparable to ammonia and reaction temperature window was towards lower temperatures. They suggested the urea could be used as an alternative of ammonia.

Although the use of ammonia is more prevalent, it has a number of disadvantages such as pure ammonia can lead to stress corrosion cracking, ammonia with a certain proportion to air is explosive (Brouwer et al., 1996). Aside from that ammonia is a very toxic gas so any leakage due to careless handling may cause serious harm to the health. Both aqueous and anhydrous forms of ammonia are toxic and their use is regulated (Albanese, 1994; Arand et al., 1982). On the other hand, the urea is non-corrosive, safer and non-regulated chemicals and as it is solid, storage, transportation and handling is much easier than ammonia and consequently urea based selective non-catalytic reduction system has been installed on more utility boilers than the ammonia-based SNCR system (Boo et al., 2001).

Unlike ammonia the documentation related to the investigations of urea are limited in the open literature, yet, so far, urea SNCR has been successfully applied to a wide variety of fuels and boilers such as coal oil and gas fired boilers, industrial boilers, refineries, and waste incinerators.

\section{3. $\mathrm{NO}_{\mathrm{x}}$ Reduction Performance with Urea}

The capabilities of urea based SNCR were investigated in two large pulverized coal fired boilers. One unit was Georgia Power Company's Hammond unit 4, located in Rome Georgia and another one was Wansley unit 1, located in Roopville, Georgia. Hammond unit 4 was a wall fired 500 MW foster wheeler unit that had been retrofitted with foster wheeler low $\mathrm{NO}_{\mathrm{x}}$ burners and over fire air and Wansley unit 1 was a twin furnace, tangentially fired $880 \mathrm{MW}$ combustion engineering unit that had been retrofitted with ABB C-E service's Low $\mathrm{NO}_{\mathrm{x}}$ concentric firing system level 2 . At plant Wansley, the average exit temperature was in excess of $1555 \mathrm{~K}$ at full load condition and plant Hammond unit 4 at full load condition the average exit temperature was in excess of $1333 \mathrm{~K}$. Test demonstrated that at an NSR of 1.0, for Hammond unit 4, 30 to $35 \% \mathrm{NO}_{\mathrm{x}}$ reduction was obtained maintaining an ammonia slip below $5 \mathrm{ppm}$ and for other case only $22 \%$ reduction was observed with an ammonia slip of 6 ppm (Eddings et al., 1998).

In 1999, urea based SNCR system has been first retrofitted in two existing 250 MW coal fired boilers at Honam power Plant in Yosu, Korea. Both boilers were Babcock and Wilcock opposing wall fired using low sulfur coal $(<0.5 \%$ coal $)$ as fuel. In case of unit 1 , during test the base line $\mathrm{NO}_{\mathrm{x}}$ was $462 \mathrm{ppm} @ 6 \% \mathrm{O}_{2}$. The aqueous urea solution was injected at a NSR of 1.1 and full load condition. About $41.4 \%$ reduction was achieved, while the ammonia was about $10 \mathrm{ppm}$. In case of unit 2 at full load condition the initial $\mathrm{NO}_{\mathrm{x}}$ was recorded $416 \mathrm{ppm} @$ $6 \% \mathrm{O}_{2}$. The urea solution was injected using same NSR. The $\mathrm{NO}_{\mathrm{x}}$ reduction in this case was also $41.4 \%$, however the ammonia slip was only 4 ppm (Boo et al., 2001).

Arand et al. (1980) have conducted an experiment in a natural gas fired tunnel furnace. He created the baseline NO by adding the NO directly just before the reagent injection point. The base line NO varied from 490 to 580 ppm while the NSR ranged from 0.5 to 5.5 . He reported a maximum reduction of $95 \%$ at $1291 \mathrm{~K}$ and NSR of 5.5 for an initial $\mathrm{NO}_{\mathrm{x}}$ of $505 \mathrm{ppm}$. The preferential temperature window in his studies was appeared to be in the range of about 1140 to $1310 \mathrm{~K}$. From the literature, found that the used of urea solution have a potential in reducing emissions in Bio-fuel combustion system. This paper will describe the results comparison between the use of urea solution and ammonia liquor. The analysis was performed in Normalized Stoichiometric Ratio (NSR).

\section{Experimental Setup and Procedure}

A schematic diagram of the experimental set up is shown in Figure 1. The complete experimental set up mainly consists of burner, combustor and injection system. A Riello brand 40G series-G10 light oil industrial burner was used for the experiment as a combustion source. All tests were conducted using Bio-fuel (B5\% - 5\% of palm oil and $95 \%$ commercial diesel) as fuel. Fuel was injected at the back plate using central fuel injector with single fuel nozzle pointing axially outwards. A circular pilot-scale combustor or combustion chamber was used for the present experiment. The length and the outside diameter of the combustor were $1765 \mathrm{~mm}$ and $390 \mathrm{~mm}$ respectively. The material was $2.5 \mathrm{~mm}$ mild steel sheet. To reduce the heat transfer in order to get high temperature inside the combustor as well as to protect the combustion chamber wall being overheated, a $50 \mathrm{~mm}$ refractory lining of KIMCAST LW 11 material was used. Injector for reagent injection was placed at the downstream of the flame zone, i.e. at post combustion zone as SNCR is concerned with the post combustion flue gas treatment. Usually, in the injection zone the $\mathrm{NO}_{\mathrm{x}}$ reducing reagent is injected into the combustion effluent from a single or multiple injectors. In this zone also most of the reagent is mixed with the flue gas. A $70^{\circ}$ cone spray dual fluid injector was used in the present studies. The injection zone started from $700 \mathrm{~mm}$ downstream of the burner end and continued up to about $1100 \mathrm{~mm}$. At the injector section one temperature tapping was made in order to provide the facility to measure the temperature of injection 


\section{Results and Discussions}

Experiments were performed using 5\% aqueous urea and ammonia solution to investigate the $\mathrm{NO}_{\mathrm{x}}$ reduction, effective temperature window and peak temperature of $\mathrm{NO}_{\mathrm{x}}$ reduction with the variation of injection temperature, residence time and normalized stoichiometric ratio. The tests were performed in a range of Normalized Stoichiometric Ratio (NSR) from 1 to 4, temperatures from 973 to $1323 \mathrm{~K}$ and residence time for $815 \mathrm{~mm}$ of reactor.

\subsection{Effect of Normalized Stoichiometric Ratio}

The Figure 2 shows the effect of normalized stoichiometric ratio on $\mathrm{NO}_{\mathrm{x}}$ reduction for $5 \%$ urea and ammonia solution at an injection temperature of $1093 \mathrm{~K}$ and NSR of 4 . Both profiles show that the $\mathrm{NO}_{\mathrm{x}}$ reduction increased with increasing value of NSR. However, in case of ammonia the reduction rate was higher within the investigated range of NSR. Another significant feature is that between NSR of about 1 to 3.3, urea achieved better reduction rate than ammonia but between NSR of about 3.3 to 4, ammonia was observed to be effective $\mathrm{NO}_{\mathrm{x}}$ reducing reagent at the investigated injection temperature. This might have occurred due to following causes:

For a particular concentration of reagent, to maintain a certain value of NSR, injection rate of urea will be about twice as much as ammonia since the molecular weight of urea is more than ammonia. So, at a particular value of NSR, the droplets of ammonia will be finer than urea. Between NSR of 1 to 3, the droplets produced by ammonia were too fine to have sufficient flow momentum in order to penetrate effectively in to the flue gas and thus resulted in reduced $\mathrm{NO}_{\mathrm{x}}$ reduction than urea. In contrast, between NSR of about 3.3 to 4 , injected amount of urea produced too coarse droplets with respect to the investigated temperature to get better output than ammonia. This happens because coarser droplets than optimum size take longer time to become in contact with the nitric oxide of the flue gas as water, which surrounds the droplets, is more in case of coarser droplets and takes longer time to be evaporated.

In the present study in case of ammonia, between NSR of 3.3 to 4 , the fall of $\mathrm{NO}_{\mathrm{x}}$ reduction rate was quite insignificant as compared to urea, which suggests that at higher NSR i.e. more than 4 , ammonia could give significant reduction at the investigated injection temperature.

\subsection{Effect of Residence Time}

Figures 3 and Figure 4 shows the comparison of the $\mathrm{NO}_{\mathrm{x}}$ reaction profile as a function of residence time of reagent-flue gas mixture between 5\% ammonia and urea solution at an injection temperature of $1093 \mathrm{~K}$ and NSR of 4. The both profiles show that the $\mathrm{NO}_{\mathrm{x}}$ reduction increased with increase in residence time. Up to the residence time of $283 \mathrm{~ms}$ in case of both profiles, the reduction was moderate, however, afterwards with further increase in residence time the reduction rate decreased gradually and tended to be flat. Over a first $283 \mathrm{~ms}$ residence time, the reduction rate of ammonia was sharper than urea, however, afterward urea had higher reduction rate. This can be explained as follows:

In case of ammonia the peak temperature of $\mathrm{NO}_{\mathrm{x}}$ reduction is $1063 \mathrm{~K}$ and that for urea is $1128 \mathrm{~K}$, so within 283 $\mathrm{ms}$ the reactors temperatures were around $1063 \mathrm{~K}$ and thus ammonia resulted in higher rate of $\mathrm{NO}_{\mathrm{x}}$ reduction as compared to urea.

Apart from the low temperature effect, this rate might decrease due to low reagent-flue gas ratio. As the residence time increases the amount of active reagent to flue gas decreases along the downstream of the reactor, which may cause poor reaction performance. In case of urea, as in the first $283 \mathrm{~ms}$ of residence time the reduction rate was smaller than ammonia, so at the downstream of the combustion chamber the reagent-flue gas ratio was obviously higher for urea case than ammonia, which might cause the higher reduction rate at the downstream of the combustion chamber compared to ammonia.

The tendency of being flat for both profiles at the downstream of the reactor suggests that depending on the operating conditions and geometry of the reactor after a certain length the reactor has no significant role in reducing $\mathrm{NO}_{\mathrm{x}}$.

\subsection{Effect on Injection Temperature}

Figures 5 and Figure 6 shows the reduction and initial concentration of $\mathrm{NO}_{\mathrm{x}}$ as a function of injection temperature for $5 \%$ urea and ammonia solution at NSR of 4 . The figure shows that for both cases, up to a certain temperature $\mathrm{NO}_{\mathrm{x}}$ reduction continued to increase with increasing injection temperature and afterward the reduction decayed with further increase in temperature. The decay was sharper in case of ammonia.

In case of urea, a maximum of $54 \% \mathrm{NO}_{\mathrm{x}}$ reduction was achieved at a temperature of $1128 \mathrm{~K}$, while as for ammonia maximum reduction was $57 \%$, which was achieved at $1063 \mathrm{~K}$. So, ammonia got better $\mathrm{NO}_{\mathrm{x}}$ reduction performance as well as lower peak temperature of reduction as compared to urea.

As far as temperature window is concerned, in case of ammonia temperature window widened toward lower temperature from the peak temperature of reduction as compared to urea. Between urea and ammonia for a reduction of $53 \%$, the variation of injection temperatures was $83 \mathrm{~K}$ at lower temperature side, which demonstrated that in case of ammonia the temperature window was shifted toward lower temperature side. On 
the contrary, urea got wider temperature window toward higher temperature side from the optimum point. In higher temperature side, an equal reduction of $30 \%$ was achieved at further $132 \mathrm{~K}$ higher temperature as compared to ammonia. The above phenomenon suggests that ammonia could be applicable for lower temperature applications as compared to urea.

\section{Conclusions}

The followings are the main conclusions deduced from the investigations. The effective temperature window in the present studies is in the range of about $973 \mathrm{~K}$ to about $1300 \mathrm{~K}$. A significant result shows that for NSR, between NSR of about 1 to 3.3, urea achieved better reduction rate compare to ammonia but between NSR of about 3.3 to 4 , ammonia was observed to be effective $\mathrm{NO}_{\mathrm{x}}$ reducing reagent at the investigated injection temperature. Meanwhile for the effect of residence time, both profiles show that the $\mathrm{NO}_{\mathrm{x}}$ reduction increased with increase in residence time. Up to the residence time of $283 \mathrm{~ms}$ in case of both profiles, the reduction was moderate, however, afterwards with further increase in residence time the reduction rate decreased gradually and tended to be flat. Finally for the effect on injection temperature, for the case of urea, a maximum of $54 \% \mathrm{NO}_{\mathrm{x}}$ reduction was achieved at a temperature of $1128 \mathrm{~K}$, while as for ammonia maximum reduction was $57 \%$, which was achieved at $1063 \mathrm{~K}$. So, ammonia got better $\mathrm{NO}_{\mathrm{x}}$ reduction performance as well as lower peak temperature of reduction as compared to urea. The study on the difference aqueous solution can be further investigate using wider temperature range to look the effect in low and high temperature profile.

\section{References}

Albanese, V., Kellogg, G. and Eisenmann, D. R. (1994). The Clean Air Advisor. NALCO/FUEL TECH, Naperville, IL. 3(2): 1-6.

Arand, J .K., Muzio, L. J. and Teixeira, D. P. (1982). Urea Reduction of NOx in Fuel Rich Combustion Effluents. (U.S. 4,325,924).

Arand, J. K., Muzio, L. J., and Sotter, J. G., (1980). Urea Reduction of NO $O_{x}$ in Combustion Effluents. (U.S. 4,208,386).

Boo, M. C., Eoe, S. H., Jang, W. C., Jo, Y. D., Yang, D. C., Park, J. B., Paul G. Carmingnani, PE, Sun W. H. (2001). First Installation of Selective Non-Catalytic $\mathrm{NO}_{\mathrm{x}}$ Reduction Process on Utility Boilers in Korea. U.S.EPA/DOE/EPRI Mega Symposium 2001 MEGA Symposium, Chicago, IL.

Brouwer, J., Heap, M.P., Perishing, D.W. and Smith P.J. (1996). A Model for Prediction of Selective Non-Catalytic Reduction of Nitrogen Oxides by Ammonia, Urea and Cyanuric Acid with Mixing Limitations in the presence of CO. The Proceedings of Sixth international Symposium on Combustion. Naples, Italy.

Caton, J. A. and Seibers, D. L. (1989). Reduction of Nitrogen Oxides in Engine Exhaust Gases by the Addition of Cyanuric Acid. Journal of Eng. for Gas Tturbines and Power. (111): 393-398.

Chen, S. L., Cole, J. A., Heap, M. P., Kramlich, J. C., Mc Carthy, J. M. and Pershing, D.W. (1988), Advanced $\mathrm{NO}_{\mathrm{x}}$ Reduction Processes Using - $\mathrm{NH}$ and - $\mathrm{CN}$ Compounds in Conjunction with Staged Addition. The Proceedings of Twenty-Second Symposium (International) on Combustion, The Combustion Institute, Pittsburgh. 1135-1145.

Eddings, E., Cremer, M., Hardman, R., Cox, J., Martz, T., Muzio, L., Quartucy, G. and Stallings, J. (1998). U. S. DOE SCR and SNCR for NO Control Conference.

Ishak, M.S.A., Jaafar, M.N.M. (2011). The Reduction of Noxious Emissions Using Urea Based on Selective Non-Catalytic Reduction in Small Scale Bio Fuel Combustion System. Modern Applied Science. Vol. 5, No. 2:108-112, doi:10.5539/mas.v5n2p108, http://dx.doi.org/10.5539/mas.v5n2p108

Jodal, M., Nielsen, C., Hulgaard, T. and Dam-Johansen, K. (1990). Pilot-Scale Experiments with Ammonia and Urea as Reductants in Selective Non-Catalytic Reduction of Nitric Oxide. 23rd Symposium (International) on Combustion. Pittsburgh: The Combustion Institute, 237-243.

Rota, R., Antos, D., Zanoelo, E. F., Morbidelli, M. (2002). Experimental and Modeling Analysis of the $\mathrm{NO}_{\mathrm{x}} \mathrm{OUT}$ Process. Chemical Engineering Science. (57): 27-38.

Saliman, S. and Hanson, R. K. (1980). Kinetic Study of NO Removal from Combustion Gases by $\mathrm{NH}_{\mathrm{i}}-$ Containing Compound. Combustion Science and Technology. (23): 225-230. 


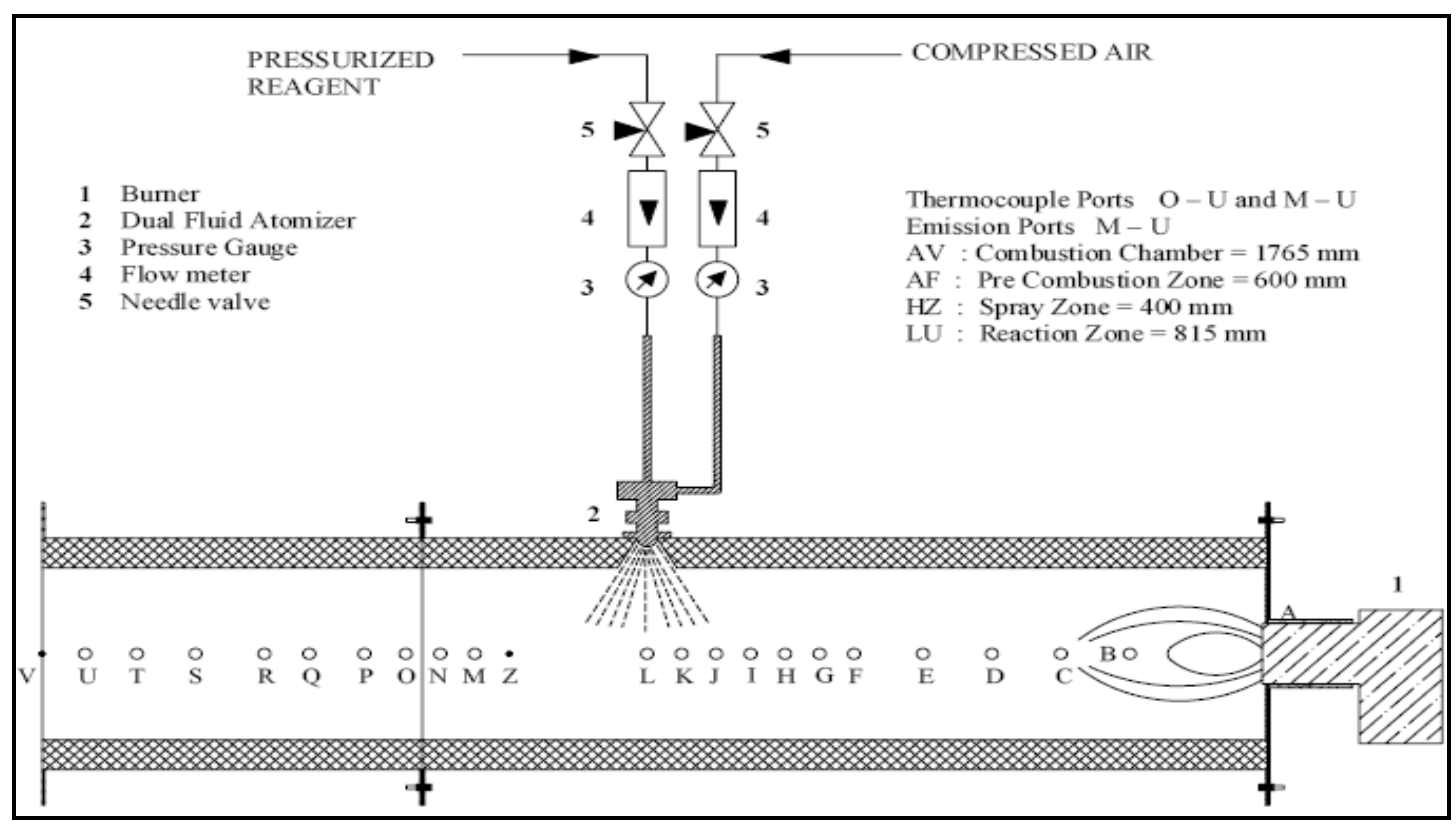

Figure 1. Layout of the Experimental Set Up

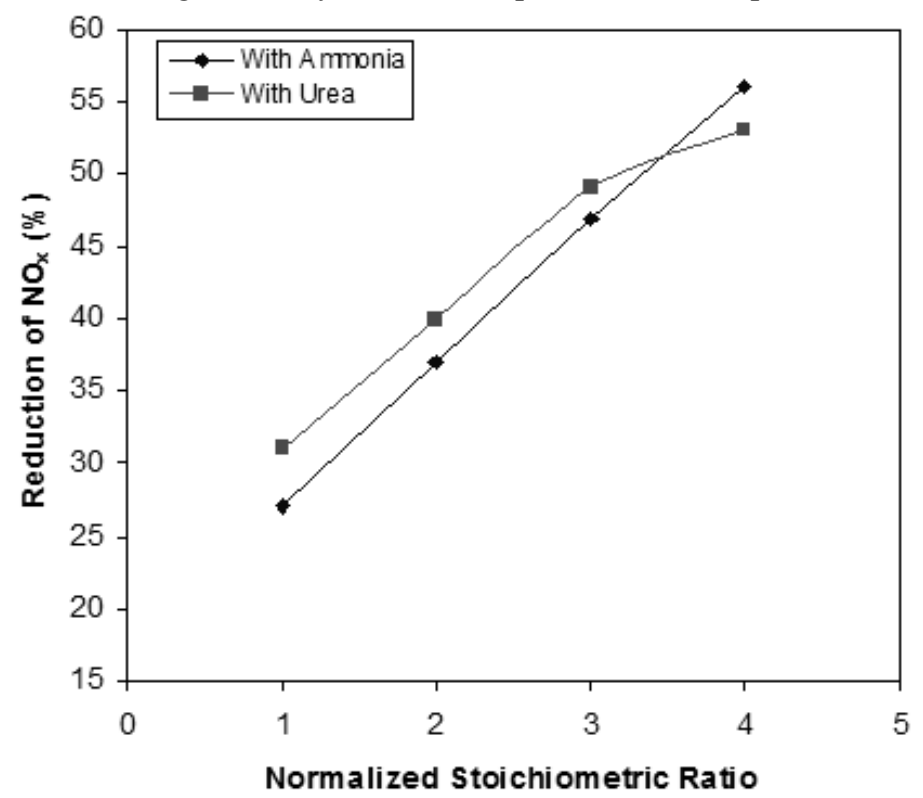

Figure 2. Comparison of reduction vs. NSR profile between aqueous urea and ammonia liquor at $1093 \mathrm{~K}$ 


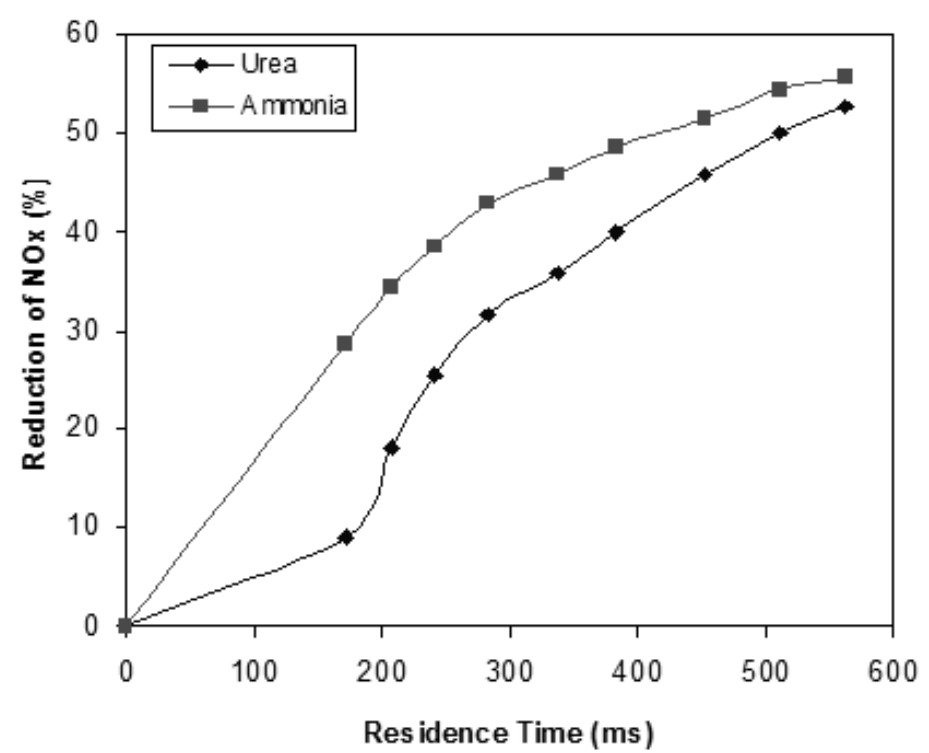

Figure 3. Comparison between aqueous urea and ammonia liquor in terms of NOx reduction vs. residence time profiles at $1093 \mathrm{~K}$ and NSR of 4

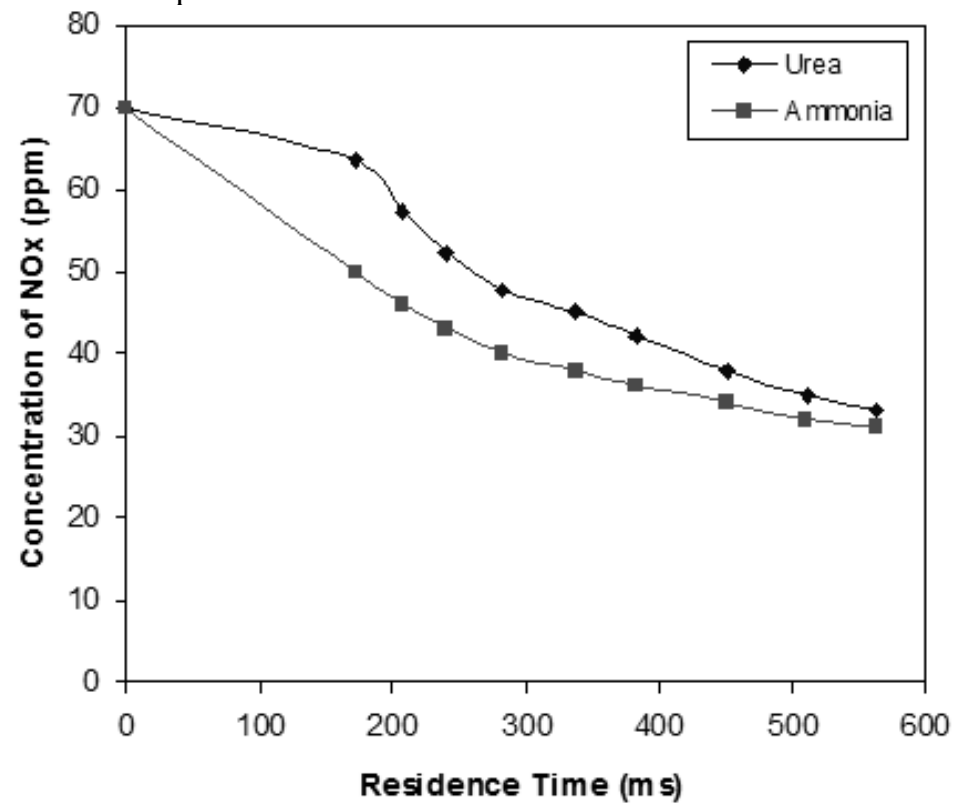

Figure 4. Comparison between aqueous urea and ammonia liquor in terms of reaction profiles at $1093 \mathrm{~K}$ and NSR of 4 


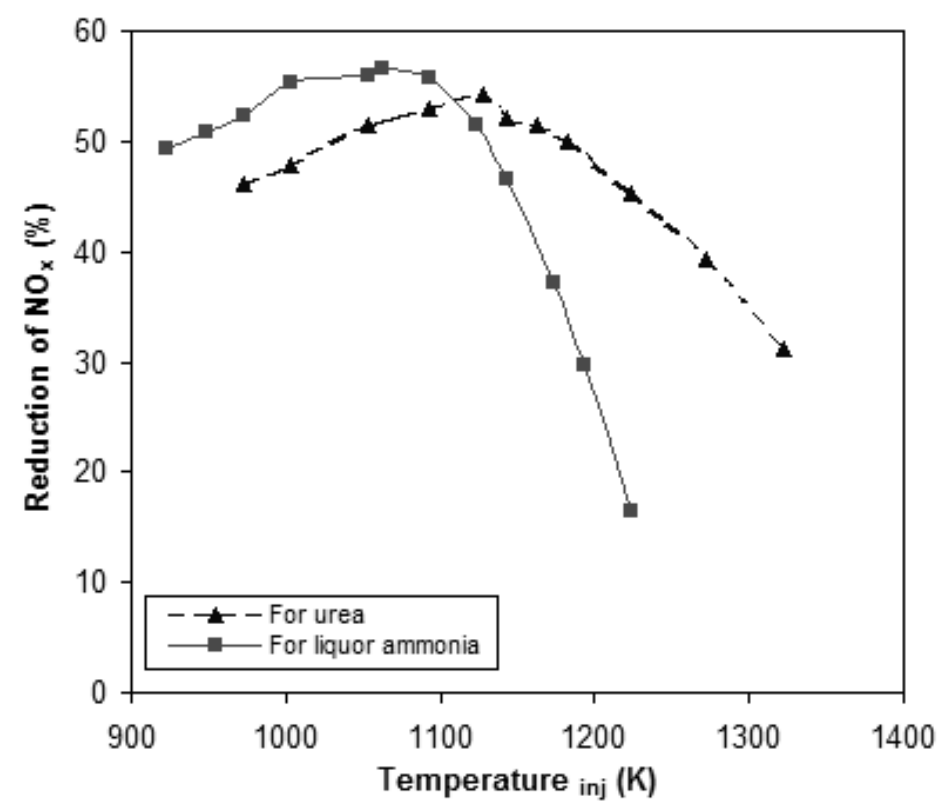

Figure 5. Comparison of reduction characteristics of urea and ammonia liquor at NSR of 3

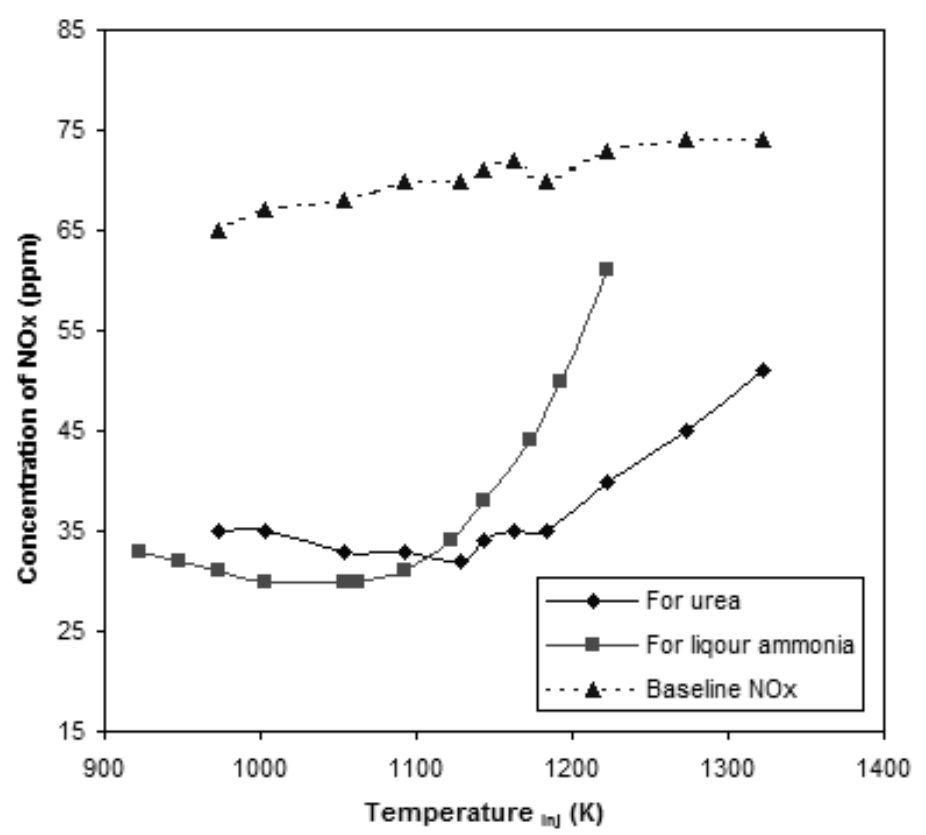

Figure 6. Comparison of reduction characteristics of urea and ammonia liquor with respect to base line value at NSR of 3 